\title{
Factors Affecting Invasive Management after Unplanned Extubation in an Intensive Care Unit
}

\author{
A Lan Lee, M.D. ${ }^{1}$, Chi Ryang Chung, M.D. ${ }^{1}$, Jeong Hoon Yang, M.D., Ph.D. ${ }^{1,2}$, \\ Kyeongman Jeon, M.D., Ph.D. ${ }^{1,3}$, Chi-Min Park, M.D., Ph.D. ${ }^{1,4}$, and Gee Young Suh, M.D., Ph.D. ${ }^{1,3}$ \\ ${ }^{1}$ Department of Critical Care Medicine, ${ }^{2}$ Division of Cardiology, Department of Medicine, ${ }^{3}$ Division of Pulmonary, Department of Medicine, ${ }^{4}$ Department of Surgery, \\ Samsung Medical Center, Sungkyunkwan University School of Medicine, Seoul, Korea
}

Background: Unplanned extubation (UE) of patients requiring mechanical ventilation in an intensive care unit (ICU) is associated with poor outcomes for patients and organizations. This study was conducted to assess the clinical features of patients who experienced UE and to determine the risk factors affecting reintubation after UE in an ICU.

Methods: Among all adult patients admitted to the ICU in our institution who required mechanical ventilation between January 2011 and December 2013, those in whom UE was noted were included in the study. Data were categorized according to noninvasive or invasive management after UE.

Results: The rate of UE was $0.78 \%$ (the number of UEs per 100 days of mechanical ventilation). The incidence of self-extubation was $97.2 \%$, while extubation was accidental in the remaining patients. Two cases of cardiac arrest combined with respiratory arrest after UE were noted. Of the 214 incidents, 54.7\% required invasive management after UE. Long duration of mechanical ventilation (odds ratio [OR] 1.52; $95 \%$ confidence interval [CI] 1.32-1.75; $\mathrm{p}=0.000)$ and high ICU mortality (OR 4.39; $95 \% \mathrm{Cl} 1.33-14.50 ; \mathrm{p}=0.015)$ showed the most significant association with invasive management after UE. In multivariate analysis, younger age $(\mathrm{OR} 0.96 ; 95 \% \mathrm{Cl} 0.93-0.99$; $\mathrm{p}=0.005$ ), medical patients (OR 4.36; $95 \% \mathrm{Cl} 1.95-9.75 ; \mathrm{p}=0.000)$, use of sedative medication (OR 4.95; 95\% Cl 1.97-12.41; $\mathrm{p}=0.001)$, large amount of secretion (OR 2.66; 95\% Cl 1.01-7.02; $\mathrm{p}=0.049$ ), and low PaO2/FiO2 ratio (OR 0.99; $95 \% \mathrm{Cl} 0.98-0.99 ; \mathrm{p}=0.000$ ) were independent risk factors of invasive management after UE.

Conclusions: To prevent unfavorable clinical outcomes, close attention and proper ventilatory support are required for patients with risk factors who require invasive management after UE.

Key Words: intensive care units; reintubation; unplanned extubation.

\section{Introduction}

Unplanned endotracheal extubation (UE) is defined as deliberate self-extubation by a patient receiving mechanical ventilation support or accidental extubation by staff nursing and medical procedures.[1] Incidence of UE of $0.5-35.8 \%$ has been re-

Received on April 30, 2015 Revised on June 5, 2015

Accepted on June 5, 2015

Correspondence to: Gee Young Suh, Division of Pulmonary and Critical Care Medicine, Department of Medicine, Samsung Medical Center, Sungkyunkwan

University School of Medicine, 81 Irwon-ro, Gangnam-gu, Seoul 06351, Korea Tel: +82-2-3410-3429, Fax: +82-2-3410-6956

E-mail: gy.suh@samsung.com

*No potential conflict of interest relevant to this article was reported. ported.[2,3] UE can lead to serious hemodynamic or airway complications, including bronchospasm, aspiration pneumonia, hypotension, arrhythmias, and cardiorespiratory arrest. [4] These complications can result in poor clinical outcomes of patients in the intensive care unit (ICU). Some studies reported prolonged mechanical ventilation and longer ICU stay and hospital stay in patients who experienced unplanned 
extubations.[4-7] In particular, reintubation after UE was associated with increased mortality.[6,8-10] However, risk factors affecting reintubation after UE have not yet been established. This study was conducted in order to assess the clinical features of patients who experienced UE and to determine the risk factors affecting invasive management after UE in ICU.

\section{Materials and Methods}

\section{1) Study design}

This study used a retrospective exploratory design and was conducted in an open room setting in adult medical intensive care units (MICU; $3 \mathrm{MICU}, 42$ beds) and surgical intensive care units (SICU; 3 SICU, 48 beds), but not the neurosurgical intensive care unit at a single center. The study was approved by the institutional review board.

\section{2) Data collection}

The charts of patients who received mechanical ventilation (MV) in MICU and SICU between January 2011 and December 2013 were reviewed. Neurosurgical patients and pediatric patients ( $\leq 18$ years) were excluded. Data were categorized according to management after UE. One was noninvasive management, including simple oxygen supply and noninvasive positive pressure ventilation (NIPPV) and the other was invasive management, including delayed intubation, immediate intubation, and cardiopulmonary resuscitation after UE. Data included patients' demographics, admission diagnosis, ventilation day, and clinical outcomes. The patients' history of sedation, use of restraints, Richmond Agitation-Sedation Scale (RASS) scores, degree of secretion, $\mathrm{PaO}_{2} / \mathrm{FiO}_{2}$ ratio ( $\mathrm{PF}$ ratio), and type of ventilator mode were used for analysis of factors affecting invasive management after UE. The number of patients who experienced UE was used to describe clinical features and outcomes of patients who experienced UE, and the number of incidents was used to determine the risk factors affecting invasive management after UE.

\section{3) Definitions}

UE was defined as the premature removal of an endotracheal tube by a patient receiving mechanical ventilation support (self extubation) or the unintentional removal of an endotracheal tube by staff during nursing and medical procedures (accidental extubation).[1] Incident was UE in MICU and SICU.

Medical or surgical patients admitted to the ICU were categorized by operation. The patients' clinical features were noted by the person who found the incident first. Patients' status without use of vasopressors was expressed as stable vital status. A large amount of secretion was explained by secretion causing a tube fixing problem on patients' face. Recurrent UE was defined as more than two times. The managements after UE were simple oxygen supply, NIPPV, immediate intubation within $1 \mathrm{hr}$ after UE, delayed intubation within $48 \mathrm{hrs}$ after UE, and cardiopulmonary resuscitation (CPR).

Weaning trial was performed according to daily assessment for spontaneous breathing trial when patients were considered clinically stable, with adequate mentation, adequate oxygenation (PF ratio $>200$ ), and adequate pulmonary function (respiratory rate $<35 / \mathrm{min}$, negative inspiratory pressure $\leq-15 \mathrm{cmH}_{2} \mathrm{O}$, tidal volume $>5 \mathrm{~mL} / \mathrm{kg}$, expiratory volume $<10-15 \mathrm{~L} / \mathrm{min}$, and no significant respiratory acidosis). Reintubation was performed according to the usual criteria (increased signs of respiratory work, for protection of the airway, persistent low $\mathrm{SaO}_{2}<90 \%$ with $\mathrm{FiO}_{2} \leq 50 \%$, or severe arterial blood gas deterioration).

\section{4) Statistical analysis}

The Statistical Package for the Social Sciences (SPSS) software, version 20.0 (SPSS Inc, Chicago, IL, USA) was used for data analysis. All categorical values were expressed as a percentage of the group from which they were derived and compared using the chi-square test and Fisher's exact test. Continuous variables were analyzed using independent Student's t test for normally distributed variables, and expressed as the mean \pm standard deviation. Univariate logistic regression analysis for screening and multivariate binary logistic regression analysis were performed for analysis of the independent risk factors affecting invasive management after UE. Two-sided $p$ values of $<0.05$ were considered statistically significant. 


\section{Results}

\section{1) Clinical features and outcomes of patients who experi- enced UE}

A total of 8,621 patients received MV in MICU and SICU

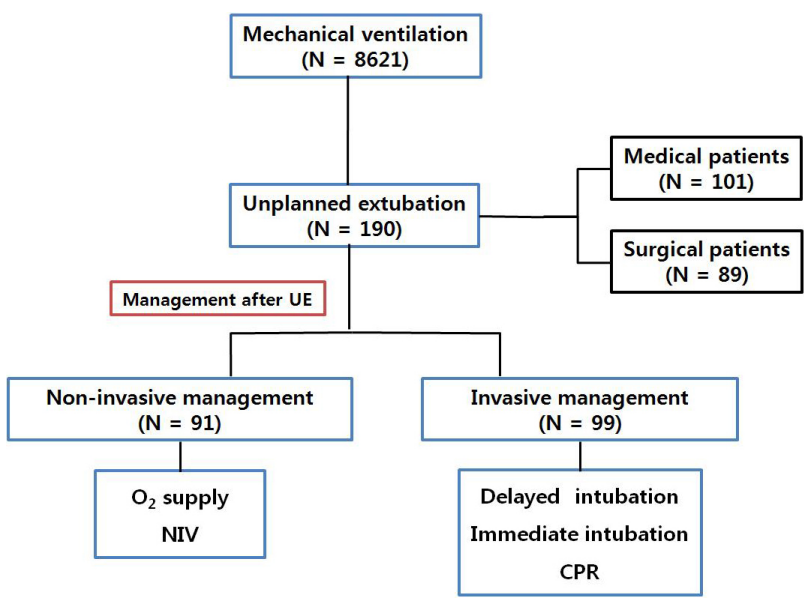

Fig. 1. Flowchart of patient selection. UE: unplanned extubation; NIV: non-invasive ventilation; CPR: cardiopulmonary resuscitation.

Table 1. Clinical features and outcomes of patients experienced unplanned endotracheal extubation

\begin{tabular}{lc}
\hline & Patients $(\mathrm{n}=190)$ \\
\hline Gender, male & $138(72.6)$ \\
\hline Age, yrs & $59.7 \pm 14.4$ \\
BMl, kg/m ${ }^{2}$ & $22.3 \pm 3.8$ \\
Medical patients & $101(53.2)$ \\
Categories of diagnosis & \\
\hline Pulmonary & $64(33.7)$ \\
Cardiovascular & $32(16.8)$ \\
Gastrointestinal & $18(9.5)$ \\
Nephrology & $13(6.8)$ \\
\hline Hepatobiliary & $12(6.3)$ \\
\hline Others & $51(26.9)$ \\
Recurrent UE & $23(12.1)$ \\
MV duration, days & $6.1 \pm 6.0$ \\
\hline Hospital length of stay, days & $50.4 \pm 80.0$ \\
ICU length of stay, days & $13.8 \pm 13.7$ \\
In hospital mortality & $92(48.4)$ \\
ICU mortality & $47(24.7)$ \\
\hline
\end{tabular}

Continuous variables are expressed as the mean \pm standard deviation. Categorical variables are expressed as number of patients (\%).

BMl: Body mass index; UE: unplanned extubation; MV: mechanical ventilation; ICU: intensive care unit.
(Fig. 1). The incidence rate of UE was $2.2 \%$ (the number of UE per 100 ventilated patients) and the incidence density of UE was $0.78 \%$ (the number of UE per 100 days of mechanical ventilation). The study included 190 patients who experienced UE. Of these, 23 patients experienced UE more than two times (Table 1). Of total patients, $53.2 \%$ were medical patients, the majority of patients had a pulmonary disease when admitted to the ICU. The mean duration of MV was 6 days, and ICU stay was almost 14 days. The ICU mortality rate was $24.9 \%$ (Table 1 ), and patients who received invasive management after UE had longer duration of MV and ICU stay than those who did not (Table 2). In addition, higher ICU and in hospital mortality were observed in the invasive management group than in the non-invasive management group. In binary logistic regression analysis, long duration of MV (odds ratio [OR] 1.52; 95\% confidence interval $[\mathrm{CI}] 1.32-1.75 ; \mathrm{p}=0.000)$ and high ICU mortality (OR 4.39; 95\% CI 1.33-14.50; $\mathrm{p}=0.015$ ) showed the most significant association with invasive management after UE (Table 3).

Table 2. Clinical outcomes of patients received invasive managements after unplanned endotracheal extubation in univariate analysis

\begin{tabular}{lccc}
\hline & $\begin{array}{c}\text { Non-invasive } \\
\text { Patients } \\
(\mathrm{n}=91)\end{array}$ & $\begin{array}{c}\text { Invasive } \\
\text { Patients } \\
(\mathrm{n}=99)\end{array}$ & p-value \\
\hline Recurrent UE & $8(8.8)$ & $15(15.2)$ & 0.179 \\
MV duration, days & $2.7 \pm 3.1$ & $9.2 \pm 6.4$ & 0.000 \\
Hospital length of stay, days & $39.5 \pm 35.7$ & $60.4 \pm 104.7$ & 0.071 \\
ICU length of stay, days & $10.1 \pm 11.3$ & $17.2 \pm 14.8$ & 0.000 \\
In hospital mortality & $29(31.9)$ & $63(63.6)$ & 0.000 \\
ICU mortality & $8(8.8)$ & $39(39.4)$ & 0.000 \\
\hline
\end{tabular}

Continuous variables are expressed as the mean \pm standard deviation. Categorical variables are expressed as number of patients (\%).

UE: unplanned extubation; MV: mechanical ventilation; ICU: intensive care unit.

Table 3. Clinical outcomes of patients received invasive managements after unplanned endotracheal extubation in mutivariate analysis

\begin{tabular}{lccc}
\hline & ${ }^{*} \mathrm{p}$-value & $\mathrm{OR}$ & $95 \% \mathrm{Cl}$ \\
\hline MV duration, days & 0.000 & 1.52 & $1.32-1.75$ \\
ICU mortality & 0.015 & 4.39 & $1.33-14.50$ \\
\hline
\end{tabular}

* $p$ values are calculated with the multivariate logistic regression analysis. OR: odds ratio; Cl: confidence interval, MV: mechanical ventilation; ICU: intensive care unit. 
Table 4. Factors associated with invasive management after unplanned endotracheal extubation in univariate analysis

\begin{tabular}{|c|c|c|c|}
\hline & $\begin{array}{c}\text { Non-invasive } \\
\text { Events } \\
(n=97)\end{array}$ & $\begin{array}{l}\text { Invasive } \\
\text { Events } \\
(\mathrm{n}=117)\end{array}$ & $p$-value \\
\hline Gender, male & $73(75.3)$ & $84(71.8)$ & 0.568 \\
\hline Age, yrs & $62.6 \pm 12.6$ & $55.6 \pm 14.9$ & 0.000 \\
\hline $\mathrm{BMl}, \mathrm{kg} / \mathrm{m}^{2}$ & $22.4 \pm 3.8$ & $22.1 \pm 3.9$ & 0.570 \\
\hline Medical patients & $40(41.2)$ & $94(80.3)$ & 0.000 \\
\hline Pulmonary disease & $27(27.8)$ & $48(41)$ & 0.044 \\
\hline MV duration before UE, days & $2.6 \pm 2.6$ & $3.0 \pm 3.6$ & 0.285 \\
\hline Cause, accidental & $2(2.1)$ & $4(3.4)$ & 0.549 \\
\hline Vital status, unstable & $29(29.9)$ & 35 (29.9) & 0.998 \\
\hline Use of restraint & $43(44.3)$ & $46(39.3)$ & 0.459 \\
\hline Use of sedative medication & $57(58.8)$ & $104(88.9)$ & 0.000 \\
\hline RASS & $-0.56 \pm 1.87$ & $-0.15 \pm 1.72$ & 0.102 \\
\hline Large amount of secretion & $10(10.3)$ & $30(25.6)$ & 0.004 \\
\hline PF ratio & $290.0 \pm 117.1$ & $197.3 \pm 88.1$ & 0.000 \\
\hline Weaning & $8(8.2)$ & $1(0.9)$ & 0.007 \\
\hline $\begin{array}{l}\text { Ventilator mode, pressure } \\
\text { control }\end{array}$ & $6(6.2)$ & $24(20.5)$ & 0.003 \\
\hline
\end{tabular}

Continuous variables are expressed as the mean \pm standard deviation. Categorical variables are expressed as number of patients (\%).

BMl: Body mass index; MV: mechanical ventilation; UE: unplanned extubation; RASS: Richmond Agitation-Sedation Scale scores; PF: PaO2/FiO2.

\section{2) Factors associated with invasive management after UE}

Of the 214 incidents, $54.7 \%$ were invasive management after UE. Delayed intubation, immediate intubation, and CPR as invasive management were $8.4 \%, 45.3 \%$, and $0.9 \%$ of total incidents, respectively. Simple oxygen supply and NIPPV as non-invasive management after UE were $36.0 \%$ and $9.3 \%$ of total incidents. The majority of incidents were self extubations (97.2\%). Restraint was used in almost half of the total of 214 incidents, and sedative medication was used in $75.2 \%$. Of total incidents, $81.8 \%$ received MV with pressure support mode.

Invasive management after UE was necessary in younger patients, medical patients, patients with pulmonary disease, with low PF ratio, with large amount of secretion, and with pressure-controlled ventilator mode (Table 4). In addition, the invasive management group included more patients using sedative medication and who did not receive a weaning trial than the non-invasive management group (Table 4). In
Table 5. Factors associated with invasive management after unplanned endotracheal extubation in multivariate analysis

\begin{tabular}{lccc}
\hline & ${ }^{*} \mathrm{p}$ value & OR & $95 \% \mathrm{Cl}$ \\
\hline Age, yrs & 0.005 & 0.96 & $0.93-0.99$ \\
Medical patients & 0.000 & 4.36 & $1.95-9.75$ \\
Use of sedative medication & 0.001 & 4.95 & $1.97-12.41$ \\
Large amount of secretion & 0.049 & 2.66 & $1.01-7.02$ \\
PF ratio & 0.000 & 0.99 & $0.98-0.99$ \\
\hline
\end{tabular}

${ }^{*} p$ values are calculated with the multivariate logistic regression analysis. OR: odds ratio; Cl: confidence interval; PF: PaO2/FiO2.

multivariate binary logistic regression analysis, younger age (OR 0.96; 95\% CI 0.93-0.99; $\mathrm{p}=0.005$ ), medical patients (OR 4.36; 95\% CI 1.95-9.75; $\mathrm{p}=0.000$ ), use of sedative medication (OR 4.95; 95\% CI 1.97-12.41; $\mathrm{p}=0.001$ ), large amount of secretion (OR 2.66; 95\% CI 1.01-7.02; $\mathrm{p}=0.049$ ), and low PF ratio (OR 0.99; 95\% CI 0.98-0.99; $\mathrm{p}=0.000$ ) were independent risk factors in invasive management after UE (Table 5).

Of total 134 medical patients, 70.1\% was received invasive managements after UE. Use of sedative medication, low PF ratio, and pressure-controlled ventilator mode were associated with invasive managements after UE in medical patients. On multivariate analysis, low PF ratio (OR 0.993; 95\% CI 0.988-0.997; $\mathrm{p}=0.001$ ) was significantly associated with invasive management after UE in medical patients. Of total 80 surgical patients, $28.8 \%$ was received invasive management after UE. Male, younger age, pulmonary disease, long duration of MV before UE, use of sedative medication, large amount of secretion, low PF ratio, and pressurecontrolled ventilator mode were associated with invasive managements after UE in surgical patients. Of these factors, younger age (OR 0.874; 95\% CI 0.782-0.976; $\mathrm{p}=0.017$ ) and low PF ratio (OR 0.978; 95\% CI 0.961-0.996; $\mathrm{p}=0.017$ ) were independent risk factors in surgical patients requiring invasive management after UE.

\section{Discussion}

This study reported on clinical features and outcomes of patients who experienced UE, clinical outcomes of patients who received invasive management after UE, and factors associated with invasive management after UE. 
Incidence of events of $0.78 \%$ in this study was consistent with rates reported in the previous studies, ranging from $0.1 \%$ to $3.6 \%$ UE per 100 ventilation days.[2-3,11] Previous studies on UE have reported association of UE with longer stays and duration of mechanical ventilation.[4-7,12] Moreover, in recent studies UE in surgical or medical ICU was associated with high ICU and in-hospital mortality rates. $[10,13]$ Many previous studies have reported risk factors for UE. In previous studies, presence of agitation, higher level of consciousness, inadequate sedation, use of benzodiazepines, Acute Physiology and Chronic Health Evaluation II score $\geq 17$, nursing care, use of physical restraints, and insufficient endotracheal tube fixation were risk factors for UE. [1,4,7,12,14-18]

Reintubation after UE was associated with higher hospital costs, demanded more chronic care, and had a greater incidence of ventilator-associated pneumonia (relative risk 1.8).[5,6,19] In the majority of previous studies on reintubation after UE, prolonged MV and longer ICU stay were attributed to patients who required reintubation after UE, and reintubation was associated with increased mortality in UE patients. $[6,8,9,20]$ In our study, comparing non-invasive management after UE, we found that patients who required invasive management had a significantly prolonged MV duration and high ICU mortality.

Reintubation rates after UE, which varied according to the population studied, type of UE, and level of ventilatory support, of $1.8 \%$ to $88 \%$ have been reported.[9,21] In our study, the rate of invasive management after UE was $54.7 \%$, similar to previous studies ranging from $13.3 \%$ to $78.3 \%$ in mixed-patient populations.[21] Various factors, including age older than 65 years, accidental extubation, full ventilatory support, $\mathrm{PF}$ ratio $<200$ to $250 \mathrm{mmHg}$ before unplanned extubation, Glasgow coma scale score $<11$, nonsurgical patients, diagnosis of pneumonia, and presence of $\geq 3$ comorbidities have been reported as risk factors of reintubation after UE.[8,21-24] In our study, risk factors of invasive management after UE were slightly different from those of previous studies. Unlike previous results, patients requiring invasive management after UE were younger than those in the non-invasive management group after UE. In addition, we found that a large amount of secretion was one of the risk factors for invasive management after UE. Patients with a large amount of secretion may have problems with secur- ing the endotracheal tube, and require full ventilator support.

Some studies reported that a negative RASS score and deep sedation under full MV were risk factors associated with reintubation after UE.[4,10] Although the RASS score was not a risk factor of invasive management after UE in our study, our data showed an association of sedation with invasive management after UE. We found a significant association of a medical and surgical patient with low PF ratio before UE with invasive management after UE. This result was consistent with those of several previous studies, which reported low PF ratio before UE as a risk factor for reintubation after UE.[8,10,20,25]

After UE, inappropriate management can lead to poor clinical outcome. A previous study reported on outcome of extubation failure.[13] In contrast with successful extubation, failed planned or unplanned extubation was followed by marked clinical deterioration, suggesting a direct and specific effect of extubation failure and reintubation on patient outcomes. Accordingly, more rapid intubation should be considered in patients with risk factors of invasive management after UE. Interestingly, in our study almost half of the incidents were noninvasive management after UE. This result reflects inadequate ventilatory support in many patients who received MV. Failure to identify patients who are ready for removal of MV is an important factor contributing to increased incidence of unplanned extubation. Proper application of MV and weaning protocols will probably be helpful in reducing the incidence of reintubation after UE. Therefore, risk factors of invasive management after UE should be considered, because hasty decisions regarding intubation after UE can lead to unnecessary MV and poor clinical outcome in patients without risk factors of invasive management after UE.

In conclusion, we demonstrated an association of patients requiring invasive management after UE with unfavorable clinical outcomes. Therefore, attention should be paid in order to prevent inappropriate management and unfavorable clinical outcomes in patients with risk factors of invasive management after UE. 


\section{References}

1) Moons P, Sels K, De Becker W, De Geest S, Ferdinande $\mathrm{P}$ : Development of a risk assessment tool for deliberate self-extubation in intensive care patients. Intensive Care Med 2004; 30: 1348-55.

2) Kapadia FN, Bajan KB, Raje KV: Airway accidents in intubated intensive care unit patients: an epidemiological study. Crit Care Med 2000; 28: 659-64.

3) Balon JA: Common factors of spontaneous self-extubation in a critical care setting. Int J Trauma Nurs 2001; 7: 93-9.

4) Bouza C, Garcia E, Diaz M, Segovia E, Rodriguez I: Unplanned extubation in orally intubated medical patients in the intensive care unit: a prospective cohort study. Heart Lung 2007; 36: 270-6.

5) Epstein SK, Nevins ML, Chung J: Effect of unplanned extubation on outcome of mechanical ventilation. Am J Respir Crit Care Med 2000; 161: 1912-6.

6) Krinsley JS, Barone JE: The drive to survive: unplanned extubation in the ICU. Chest 2005; 128: 560-6.

7) Chang LY, Wang KW, Chao YF: Influence of physical restraint on unplanned extubation of adult intensive care patients: a case-control study. Am J Crit Care 2008; 17: 408-15; quiz 416.

8) Chevron V, Ménard JF, Richard JC, Girault C, Leroy J, Bonmarchand G: Unplanned extubation: risk factors of development and predictive criteria for reintubation. Crit Care Med 1998; 26: 1049-53.

9) Carrión MI, Ayuso D, Marcos M, Paz Robles M, de la Cal MA, Alía I, et al: Accidental removal of endotracheal and nasogastric tubes and intravascular catheters. Crit Care Med 2000; 28: 63-6.

10) Lee JH, Lee HC, Jeon YT, Hwang JW, Lee H, Oh HW, et al: Clinical outcomes after unplanned extubation in a surgical intensive care population. World J Surg 2014; 38: 203-10.

11) Castellões TM, da Silva LD: Nursing interventions for the prevention of accidental extubation. Rev Bras Enferm 2009; 62: 540-5.

12) Atkins PM, Mion LC, Mendelson W, Palmer RM, Slomka J, Franko T: Characteristics and outcomes of patients who self-extubate from ventilatory support: a case-control study. Chest 1997; 112: 1317-23.
13) Thille AW, Harrois A, Schortgen F, Brun-Buisson C, Brochard L: Outcomes of extubation failure in medical intensive care unit patients. Crit Care Med 2011; 39: 2612-8

14) de Groot RI, Dekkers OM, Herold IH, de Jonge E, Arbous MS: Risk factors and outcomes after unplanned extubations on the ICU: a case-control study. Crit Care 2011; 15: R19.

15) Boulain T: Unplanned extubations in the adult intensive care unit: a prospective multicenter study. Association des Réanimateurs du Centre-Ouest. Am J Respir Crit Care Med 1998; 157(4 Pt 1): 1131-7.

16) Tung A, Tadimeti L, Caruana-Montaldo B, Atkins PM, Mion LC, Palmer RM, et al: The relationship of sedation to deliberate self-extubation. J Clin Anesth 2001; 13: 24-9.

17) Curry K, Cobb S, Kutash M, Diggs C: Characteristics associated with unplanned extubations in a surgical intensive care unit. Am J Crit Care 2008; 17: 45-51; quiz 52.

18) Chang LC, Liu PF, Huang YL, Yang SS, Chang WY: Risk factors associated with unplanned endotracheal self-extubation of hospitalized intubated patients: a 3-year retrospective case-control study. Appl Nurs Res 2011; 24: 188-92.

19) de Lassence A, Alberti C, Azoulay E, Le Miere E, Cheval $C$, Vincent F, et al: Impact of unplanned extubation and reintubation after weaning on nosocomial pneumonia risk in the intensive care unit: a prospective multicenter study. Anesthesiology 2002; 97: 148-56.

20) Phoa LL, Pek WY, Syap W, Johan A: Unplanned extubation: a local experience. Singapore Med J 2002; 43: 504-8.

21) da Silva PS, Fonseca MC: Unplanned endotracheal extubations in the intensive care unit: systematic review, critical appraisal, and evidence-based recommendations. Anesth Analg 2012; 114: 1003-14.

22) Jiang JS, Kao SJ, Lin CM, Yeh YW: Respiratory management after self-extubation. J Formos Med Assoc 2000; 99: 689-92.

23) Listello D, Sessler CN: Unplanned extubation. Clinical predictors for reintubation. Chest 1994; 105: 1496-503.

24) Chen $\mathrm{CZ}$, Chu YC, Lee CH, Chen CW, Chang HY, Hsiue TR: Factors predicting reintubation after unplanned 
extubation. J Formos Med Assoc 2002; 101: 542-6.

25) Razek T, Gracias V, Sullivan D, Braxton C, Gandhi R, Gupta R, et al: Assessing the need for reintubation: a prospective evaluation of unplanned endotracheal extubation. J Trauma 2000; 48: 466-9. 